\title{
Fragmentation studies by non-explosive cylinder expansion technique
}

Prakash Rao ${ }^{1}$, Jon Painter ${ }^{2}$, Gareth Appleby-Thomas ${ }^{1}$, Richard Critchley ${ }^{1,3}$, David Wood ${ }^{1}$, Andrew Roberts ${ }^{1}$ and Rachael Hazael ${ }^{1 *}$

${ }^{1}$ Centre for Defence Engineering, Cranfield University, Defence Academy of the United Kingdom, Shrivenham, SN6 8LA

${ }^{2}$ Cranfield Forensic Institute, Cranfield University, Defence Academy of the United Kingdom, Shrivenham, SN6 8LA

${ }^{3}$ University of the West of England, Engineering Design and Mathematics, Frenchay Campus, Coldharbour Lane, Bristol, BS16 1QY

${ }^{*}$ Corresponding author: Rachael.hazael@cranfield.ac.uk

\begin{abstract}
Expansion and fragmentation of metallic cylinders is an important area of study both for designing munitions and mitigation techniques against fragments as well as in the failure of pressurised pipes in industry. Most of the reported studies on fragmentation have been carried out by detonating explosively filled metallic cylinders. However, this approach has inherent limitations in terms of both safety and repeatability - not least due to packing issues with explosive fills. Fragmentation studies on hollow metallic cylinders of both mild and stainless steel of various thicknesses $(2-4 \mathrm{~mm})$ were carried out by firing a polycarbonate projectile from a single-stage light gas gun. Strain rates of the order of $2 \times 10^{4} \mathrm{~s}^{-1}$ were observed at cylinder expansion velocities of 400-450 m $\mathrm{s}^{-1}$, calculated from flash X-ray radiographs. The differences in fragmentation behaviour of both materials was observed, attributed to their different response to high strain-rate loadings.

Microscopic analysis of mild steel fragments showed interesting alignment of ferrite and pearlite grains, similar to reported effects of explosive loading. This suggests the potential to employ this technique to simulate explosive cylinder expansion in a nonexplosive laboratory environment enabling a convenient recovery of fragments. Numerical modelling with using ANSYS AUTODYN ${ }^{\circledR}$ allowed for a better
\end{abstract}


understanding of the various parameters controlling expansion and fragmentation. Analysis of recovered fragments by a Fragment Weight Distribution Map (FWDM), a method generally used for characterising pipe bombs, could clearly demonstrate the effect of casing material and thickness.

Keywords: Gas-Gun, High strain rate, Mild steel, Stainless Steel, Microstructure

\section{Introduction}

Fragmentation of metallic cylinders under high strain loading is an important subject in many military and civilian applications. For example, militarily such phenomena occur in explosive filled metallic containers representing bombs, munitions and missile warheads - whereas in the civilian context pressure burst of pipes in industrial settings is of paramount importance. Such systems are normally investigated via the use of explosive fills. Detonation of high explosives causes an intense transient loading of the casing by shock effect and detonation products. The dynamic loading drives the walls of the casing outward at high velocity, leading to deformation and subsequent fracture, producing multiple fragments (Grady, 2003). The fragmentation characteristics depend upon both the explosive fill and material properties of the casing. The challenge for a munition designer is to optimise the warhead casing to get the required fragment size, shape and velocity for the desired target effect. Testing of actual ammunition is not always feasible and hence representative experimental setups are designed to generate the requisite parametric data. Most munition systems, being cylindrical in shape, have utilised expansion tests of explosively filled metallic cylinders to characterise fragmentation (Grady, 2006; Mott, 1947; Mott and Linfoot, 1943) of different casings and explosive fills.

Studies of fragmentation (Grady, 2006; Grady and Kipp, 1985) suggest that it proceeds through random spatial and temporal occurrences of fractures. From the sites of fracture, release waves propagate away, relieving the tension within the cylinder, preventing further fracture within these regions. Fragmentation will be complete when fracture induced release waves cover the entire cylinder. Mott's theory (Mott and Linfoot, 1943) on fragmentation formed the basis for various studies 
reported worldwide in subsequent decades (Ren et al., 2016; Gold and Baker, 2008; Grady, 2006; Grady and Kipp, 1985). The theory, however, considers only one dimensional radial fragmentation without considering the length of cylinder. A different energy-based fragmentation theory of great significance was proposed by Grady et al. (Grady, 2006; Grady and Kipp, 1985). Instead of instantaneous fracture assumed by Mott, the theory considered a fracture resistance which reduces the flow stress to zero as the crack reaches some critical dimension. Grady defined a material property called fragmentation toughness, dependent on both the elastic modulus and fracture resistance of the material, to determine the size of fragments. The fragment size is directly proportional to fragmentation toughness and inversely to material density and applied strain rate. These studies predicted fragmentation irrespective of the source of impulse, i.e. explosive loading, electromagnetic effects etc.

Due to the potential large variety of casings and fillers, it is difficult to characterise their features and damage potential. Therefore, investigation of the expansion of pipe bombs for forensics research is crucial. Since it is difficult to identify energetic fillers from contaminated traces recovered from the site of an explosion, efforts have been made to characterise fragments with reference to the type of energetic filler (Oxley et al., 2018; Bors et al., 2014 and Oxley et al., 2001). In these studies, Fragment Weight Distribution Map (FWDM) based on recovered fragments was used to compare the relative power of pipe bombs. More powerful fillers produce a greater number of smaller size fragments, represented by a steeper slope in FWDM. Gregory et al. (Gregory et al., 2010) characterised pipe bomb fragments from steel pipes based on changes in their microstructure. Higher power fillers produced greater deformation in $\alpha$-ferrite and pearlite colonies. Twinning and slip bands were observed in case of high explosives like nitromethane, which are characteristic of high strain rate loading. Micro hardness of fragments also revealed direct correlation with the power of the explosive filler; a more powerful filler resulting in higher hardness. Deformation and fracture behaviour of the material changes with applied strain rates and sensitivity to strain rates also vary depending upon microstructure and mechanical properties. At high strain rates, strain hardening becomes prominent and strength of material increases until the onset of necking and subsequent fracture (Shui-Sheng et al., 2013). Moxnes et al. (Moxnes, 2014) mentions that austenitic stainless steels show significant strengthening effect at high strain rates, while ductility decreases. In similar work, Cao et al. (Cao et al., 2015) studied the effect of the strain rate (strain rate up to $10^{2} \mathrm{~s}^{-1}$ ) 
and temperature on the mechanical properties of dual phase, high strength low alloy steel (DP 800). They concluded that yield strength and tensile strength increase with strain rate at room temperature, but that these effects diminish with initial temperature. Goto et al. (Goto et al., 2008), studied explosively fragmented metal cylinders, correlated reduction in thickness of fragments to failure strain using plain strain loading condition. It was observed that fracture strain for both high strength alloy steel and plain carbon steel increased under explosive loading compared to quasi-static loading.

Experiments using a gas gun to fire a projectile into metallic cylinders to fracture failure were first reported in 1978 (Winter and Prestidge, 1978). Rubber stops within the cylinders impacted at $630 \mathrm{~m} \mathrm{~s}^{-1}$ flowed radially leading to strain rates of about $1-4 \times$ $10^{4} \mathrm{~s}^{-1}$. In experiments with mild steel cylinders of $1 \mathrm{~mm}$ wall thickness, cracks appeared at circumferential strain of 0.33 . The cracks propagated through the cylinder wall at $45^{\circ}$ to shear surface and fragment wall thickness was reduced by about $35 \%$. For comparison, the fragmentation data for naval brass cylinders in experiments by Winter et al. were analysed by Grady (Grady, 2006), using Mott's theory for the number of fragments and strain to fracture with good agreement observed, irrespective of loading approach. Vogler et al. (Vogler et al., 2016) used similar gas gun-based experiments to study dynamic fragmentation of a high strength steel alloy and a Uranium alloy, employing a polycarbonate projectile accelerated to $1900 \mathrm{~m} \mathrm{~s}^{-1}$. A variety of diagnostic tools like high speed photography, VISAR and PVDF gauges were used to record the expansion velocity and onset of cracking. A maximum radial expansion velocity of $200 \mathrm{~m} \mathrm{~s}^{-1}$ was recorded for high strength steel. The number of fragments and size distribution was analysed using Grady's energy dissipation hypothesis (Grady, 2006). The fragmentation toughness was computed based on material properties and fragment size distribution, which was similar to that obtained by the authors during comparative studies with explosively filled cylinder expansion. Simulations using a CTH hydrodynamic tool showed a good match with expansion and localised deformation but a large error in predicting the mass of individual fragments, which was attributed to the lack of an appropriate failure model.

More recently Jones et al. (Jones et al., 2012) employed a metal ogive rather than a polycarbonate insert with the aim of maximising projectile lateral momentum transfer. Strain rates of the order of $2 \times 10^{4} \mathrm{~s}^{-1}$ were obtained using a polycarbonate projectile at $900 \mathrm{~m} \mathrm{~s}^{-1}$. In subsequent work, experimental and numerical studies on expansion and 
fragmentation of aluminium and titanium alloy cylinders were presented (Jones et al., 2013) including initial work on the effects of the cylinder temperature (Jones et al., 2014). These and other similar studies (Amott et al., 2017; Stirk et al., 2009) demonstrated the potential of gas-gun approaches. There are other methodologies that investigate cylinder expansion including electromagnetic tube expansion studies where the cylinder exhibits deformation due to the employment of a cylindrical coil (Qiu et al., 2018)

Importantly, gas-gun driven cylinder expansion and fragmentation enables greater control over strain rates compared to explosive loading (as the impact velocity of the projectile can be precisely controlled), less risk for deployment of diagnostic instrumentation and the flexibility to carry out experiments in a laboratory environment. As materials behave differently under dynamic loading and that behaviour changes with the rate of loading, the characteristics at various strain rates must be established. This study aimed to build on previous work to investigate fragmentation behaviour of two types of steel (with differing microstructures), mild steel (MS) EN3 and stainless steel (SS) SS304 using the gas gun based non-explosive technique. These experiments will also investigate the effects of casing thickness and their effect on fragmentation, providing useful information for the optimisation of industrial systems as well as further development of this important technique.

\section{Materials and Method}

The experiments were carried out using a single stage 50-mm bore light gas-gun, with the experimental setup shown schematically in Figure 1.

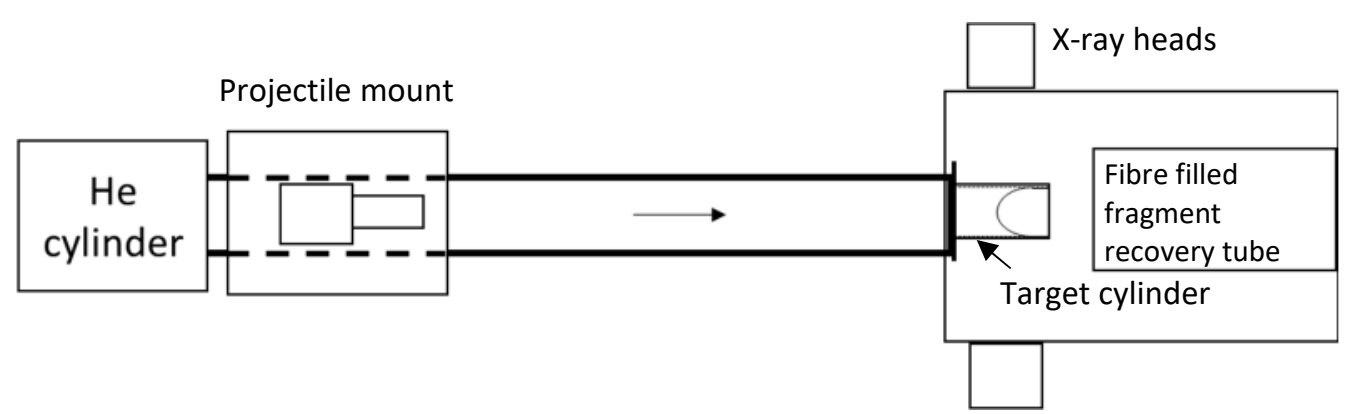

Figure 1. Schematic diagram of experimental set up (not-to-scale). 
Expansion and fragmentation of hollow cylinders of mild steel EN3 and stainless steel SS 304 was studied by firing a polycarbonate projectile $(50-\mathrm{mm}$ diameter and $60-\mathrm{mm}$ length) from the gas gun at $900 \mathrm{~m} \mathrm{~s}^{-1}$. A mild steel ogive (radius $0.02 \mathrm{~m}$ ) was placed inside the cylinder at one end and glued in position by a bead of epoxy at its base. The polycarbonate, being a soft polymeric material, was designed to preferentially flow over the (harder) ogive causing radial loading of the test cylinder, resulting in expansion and subsequent fragmentation (Figure 2).

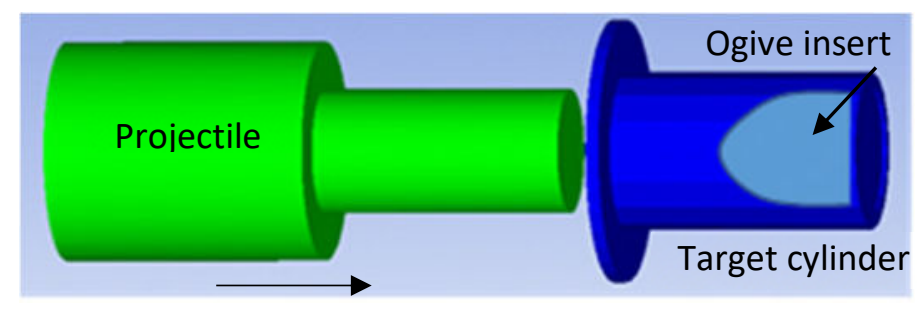

Figure 2. Model of the polycarbonate projectile impacting the steel target cylinder (arrow indicates direction of impact).

For a sub-set of experiments, a four channel flash X-ray system (Scandiflash XT-300) was used to record the expansion of cylinders at predetermined time intervals with 1 $\mu$ s accuracy, allowing subsequent calculation of the cylinder expansion velocities and strain-rates. This allowed calibration of expansion rate calculations for the other configurations. In all cases, fragments were collected in a soft recovery tube and were characterised in terms of size, mass and thickness - with experiments conducted at room temperature and pressure. Target cylinders were fabricated from commercially available mild steel (EN3) and stainless steel (SS304). EN3 is a plain carbon steel and SS 304 is a corrosion resistant alloy steel. Chemical composition of the steels is available in (ASM, 2018; Matweb, 2018).

Importantly, these materials were selected as their chemical composition, microstructure and mechanical properties are significantly different to allow interrogation of the same of subsequent fracture and fragmentation characteristics. The tensile properties determined using a Zwick 1484 Universal Testing Machine, as per standard ISO 6892, are given in Table 1. 
Table 1. Tensile properties of the steels used in the experiments.

\begin{tabular}{|c|c|c|c|}
\hline Material & $\begin{array}{c}\text { Yield Strength } \\
\mathbf{( M P a )}\end{array}$ & $\begin{array}{c}\text { Ultimate Tensile } \\
\text { Strength } \mathbf{( M P a})\end{array}$ & \% Elongation \\
\hline EN3 & 490 & 555 & 31 \\
\hline SS 304 & 345 & 660 & 76 \\
\hline
\end{tabular}

Hollow cylinders of $30-\mathrm{mm}$ inner-diameter (ID), $60-\mathrm{mm}$ length and different wall thicknesses (2-4 mm) were machined from solid stock of as received mild steel (EN3) and stainless steel (SS 304). A flange of $3 \mathrm{~mm}$ thickness and $60 \mathrm{~mm}$ outer-diameter (OD) at the mounting end of cylinder was kept for fixing the cylinder to the muzzle of the gun barrel. The cylinders were marked radially with each strip of $5 \mathrm{~mm}$ width along the length to identify the location of fragments after the experiment. A cylinder with different colours and patterns marked on it is shown in Figure 3. After the experiment, the markings could be seen on most of the fragments, enabling direct identification of the origin and direction of fragments.

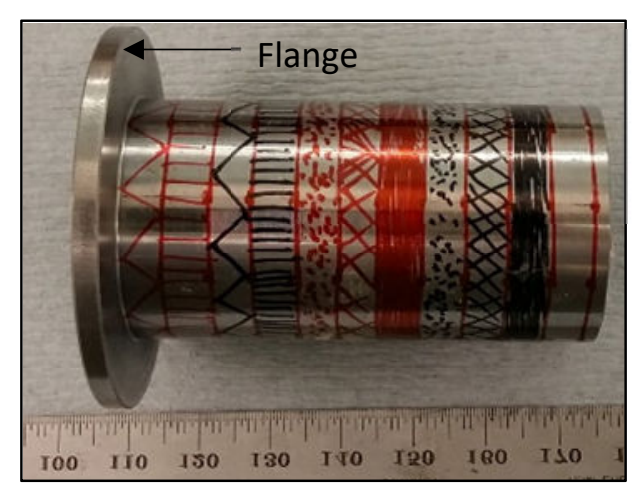

Figure 3. Example of the target cylinder pre-marked to enable post-experiment fragment source identification. 
A soft capture system comprising of fabric was used to capture the fragments for analysis after the experiment. It was noted that a relatively small number of fragments appeared to have impacted the walls of firing chamber resulting in further fracture into smaller pieces. These were identified from damaged surfaces investigated by optical microscopy and removed from calculations. The recovered fragments which had not suffered additional post-experiment damage were then characterised in terms of size, weight, reduction in wall thickness and their original location on cylinder to enable the construction of FWDM.

3D simulations were performed using hydrodynamic code ANSYS AUTODYN V16.2, to study the effect of casing material and thickness on expansion velocity. Mild Steel (1006), Stainless steel (SS304), and polycarbonate were selected from the AUTODYN® material library. The details of modelling parameters are given in Table 2

Table 2. Material modelling parameter for numerical study.

\begin{tabular}{|l|c|l|c|}
\hline \multicolumn{1}{|c|}{ Material } & $\begin{array}{c}\text { Eq. of state } \\
\text { (EOS) }\end{array}$ & \multicolumn{1}{|c|}{ Strength model } & $\begin{array}{c}\text { Failure } \\
\text { model }\end{array}$ \\
\hline Mild Steel (1006) & Shock & Johnson-Cook & - \\
\hline $\begin{array}{l}\text { Stainless Steel (SS } \\
\text { 304) }\end{array}$ & Shock & Steinberg-Guinan & - \\
\hline Polycarbonate & Shock & Piecewise JC & Plastic strain \\
\hline
\end{tabular}

Johnson Cook (JC) strength model, which is most widely used for high strain rate effects, relates the flow stress to plastic strain, strain rate, strain-rate hardening and temperature. Steinberg Guinan strength model is similar to JC model, relating yield strength to plastic strain, strain rates, strain rate hardening and temperature. However, Steinberg Guinan model postulates that yield strength initially increases with strain rates, reaches a maximum at strain rates of about $10^{5} \mathrm{~s}^{-1}$, and then becomes independent of loading rate. Stainless steel has also been reported to follow this behaviour (Steinberg et al; 1980). 


\section{Results and discussion}

A total of eight experiments were carried out, one each with three different wall thicknesses (2, 3 and $4 \mathrm{~mm}$, respectively) of both the materials and a repeat of the 4$\mathrm{mm}$ wall thickness cylinders. The velocity of the projectile was kept constant throughout at $915 \pm 15 \mathrm{~m} \mathrm{~s}^{-1}$, measured using a sequence of light gates immediately prior to projectile impact. Radiographs were successfully obtained for two experiments with $4 \mathrm{~mm}$ thick mild steel cylinders and for one of the $4 \mathrm{~mm}$ stainless steel samples, providing validation of expansion rate estimates and - importantly - direct visualisation of material expansion.

Expansion velocity of the $4 \mathrm{~mm}$ stainless steel cylinder was computed from flash $\mathrm{X}$ ray radiographs by measuring the bulge height at different time intervals. A change in the radius during a known time interval gave the wall expansion velocity. Radiographs at $5 \mu$ s time intervals for one of the mild steel cases are shown in Figure 4 (3 radiographs due to a miss-fire of one X-ray tube). In the second such experiment (Figure 5), the time interval between the X-ray heads was set as $10 \mu \mathrm{s}$, however only two radiographs were obtained. In turn, Figure 6 shows the expansion of the stainless steel.

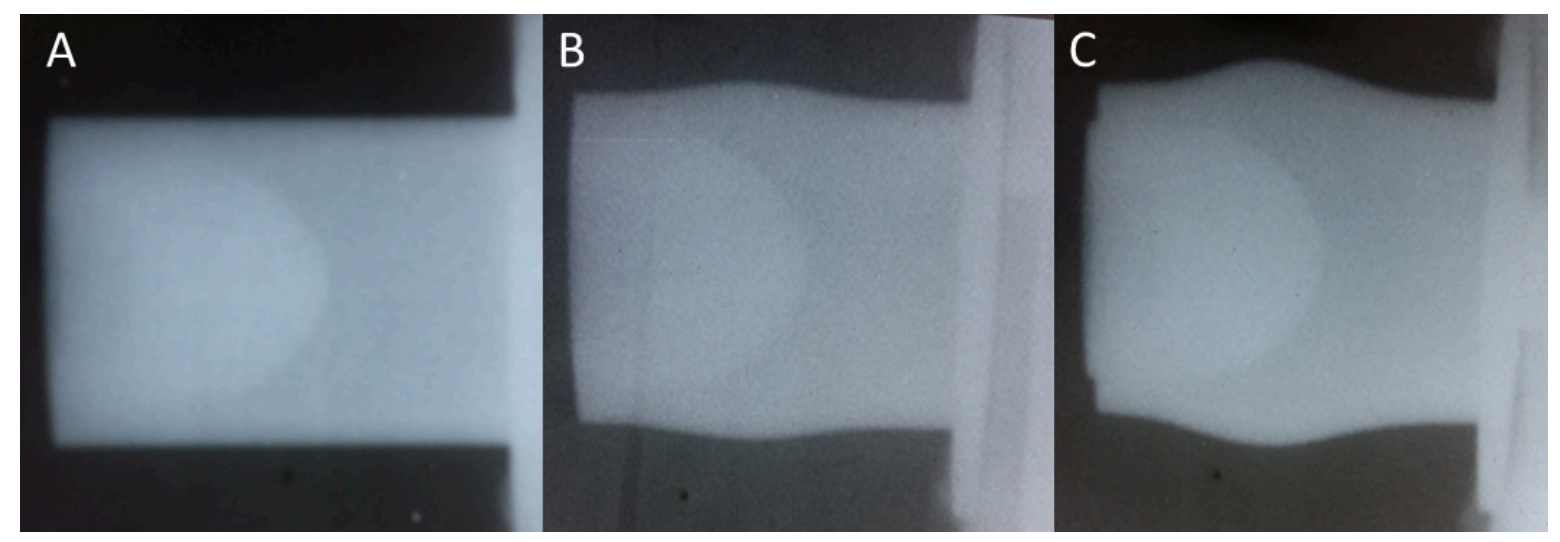

Figure 4. A) $t=0 \mu \mathrm{s} ; \mathrm{r}=19.00 \mathrm{~mm} \mathrm{~B}) \mathrm{t}=5 \mu \mathrm{s} ; \mathrm{r}=20.72 \mathrm{~mm}$ and $\mathrm{C}) \mathrm{t}=10 \mu \mathrm{s} ; \mathrm{r}=$ $22.70 \mathrm{~mm}$. Radiographs illustrating 4-mm thick mild steel cylinder expanding (where $r$ denotes peak radial dimension at a given time step, $t$ ). 


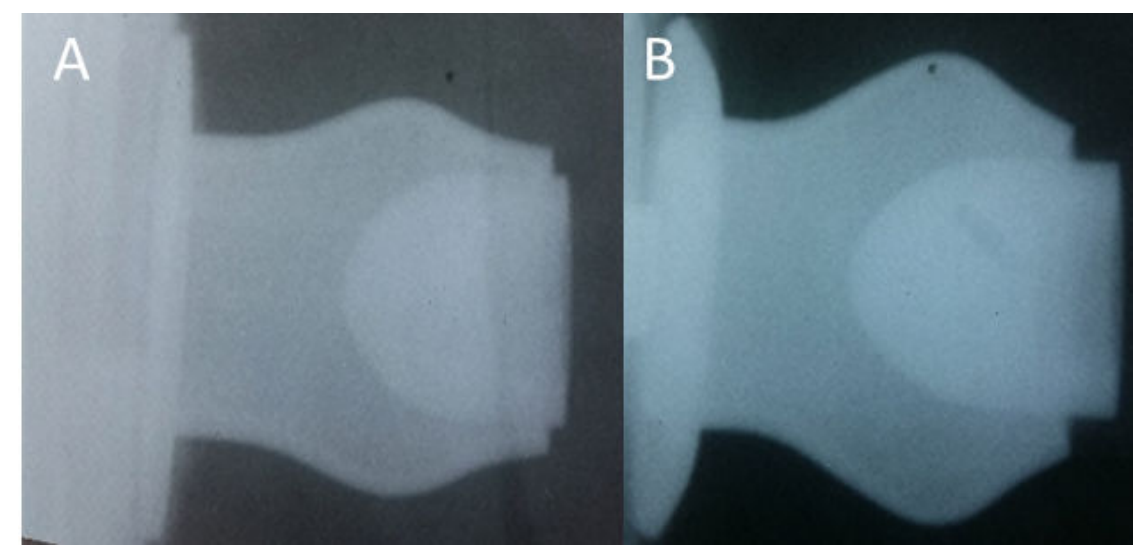

Figure 5. A) $10 \mu \mathrm{s} ; \mathrm{r}=23.89 \mathrm{~mm}$ and B) $20 \mu \mathrm{s} ; \mathrm{r}=27.81 \mathrm{~mm}$. Radiographs illustrating the repeatability of the expansion of the 4-mm thick mild steel thick cylinders (where $r$ denotes peak radial dimension at a given time step, $t$ ).

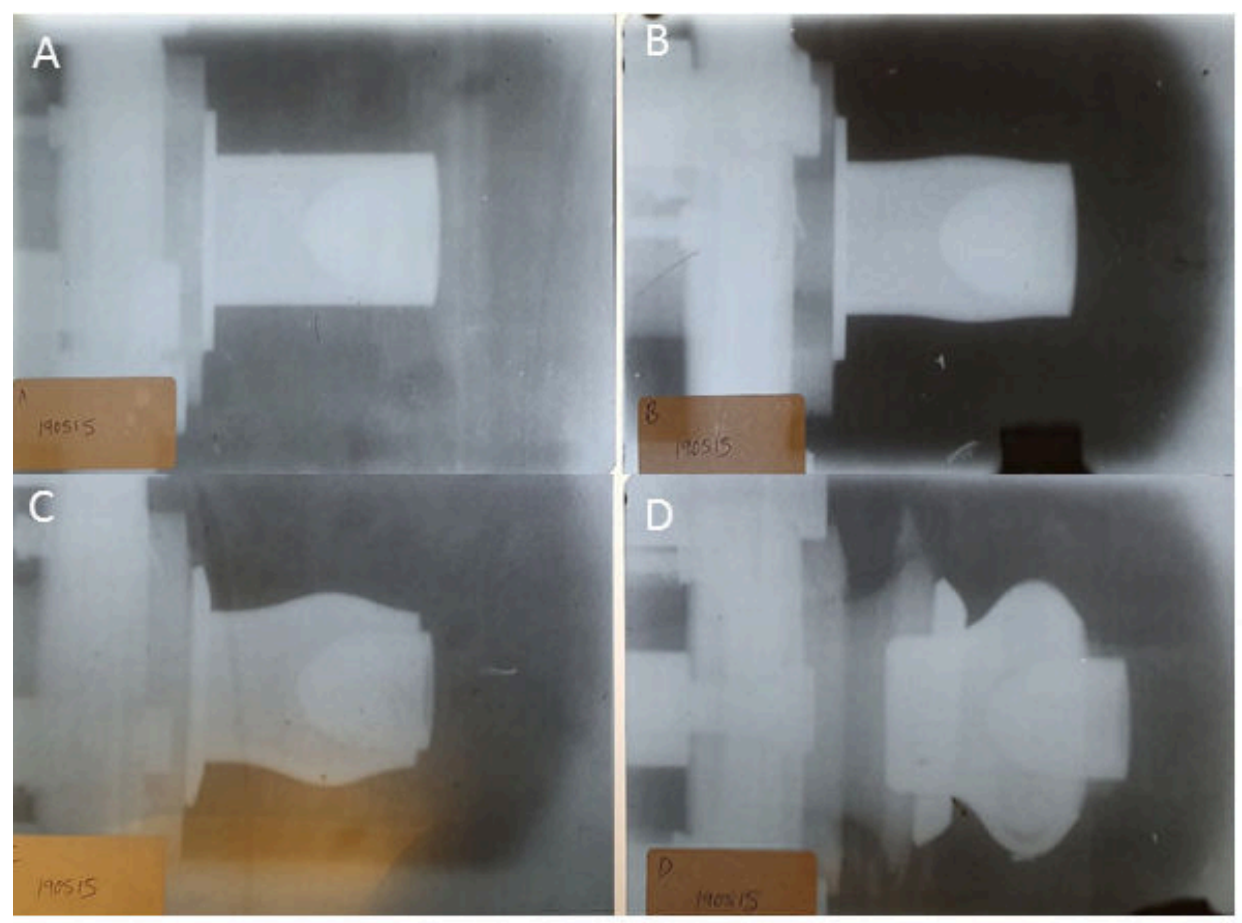

Figure 6. Radiographs illustrating 4-mm thick stainless steel cylinder expanding (where $r$ denotes peak radial dimension at a given time step, $t$ ). $A t=0 \mu s ; r=19.0$ $\mathrm{mm}, \mathrm{B} \mathrm{t}=20 \mu \mathrm{s} ; \mathrm{r}=21.03 .0 \mathrm{~mm}, \mathrm{C} \mathrm{t}=40 \mu \mathrm{s} ; \mathrm{r}=25.17 .0 \mathrm{~mm}$ and $\mathrm{D} \mathrm{t}=90 \mu \mathrm{s} ; \mathrm{r}=$ $35.52 \mathrm{~mm}$. Note, exposure times greater than those considered in Figures 4 and 5 to provide later-time information. 
The consistently symmetric radial expansion until relatively late times (ca. $100 \mu \mathrm{s}$ ) is notable from Figures 4 to 6 , with the X-rays taken at different angles, suggesting good general alignment. Although it is to be noted the creation of a void The expansion velocity has been shown to accelerate to a maximum at a rate dependent on the material properties and strain-rates (Jones et al., 2013; Jones et al., 2012; Vogler et al., 2003). Measurements made from Figures 4 and 5 give expansion velocities of 344 and $392 \mathrm{~m} \mathrm{~s}^{-1}$, for the time intervals $0-5 \mu \mathrm{s}$ and $10-20 \mu \mathrm{s}$ respectively,- a velocity increase of $14 \%$. Calculated strain rates are $1.94 \times 10^{4} \mathrm{~s}^{-1}$ and $2.06 \times 10^{4} \mathrm{~s}^{-1}$. The latter stages of the expansion of the mild steel cylinders were not captured due to misfiring of the X-ray tubes. For Figure 6 and the 4-mm thick stainless steel cylinders, the expansion velocity was $102 \mathrm{~m} \mathrm{~s}^{-1}$ between $0-20 \mu \mathrm{s}$ before stabilising at $207 \mathrm{~m} \mathrm{~s}^{-1}$ for the latter two time steps. , This gives an initial strain rate of $0.5 \times 10^{4} \mathrm{~s}^{-1}$ before it stabilises at $1.09 \times 10^{4} \mathrm{~s}^{-1}$. The difference in the material responses of the two materials can be highlighted by comparison of the average strain rates between 0 $20 \mu \mathrm{s} ; 0.5 \times 10^{4} \mathrm{~s}^{-1}$ for stainless steel and $2.32 \times 10^{4} \mathrm{~s}^{-1}$ for the mild steel. This indicates that although the yield strength for stainless steel is lower than mild steel at quasi-static conditions (Table 1), under dynamic loading the stainless steel is stronger. In general, the strain rates calculated above are consistent with rates encountered for gas-gun driven experiments elsewhere (Jones et al., 2012; Vogler et al., 2003).

Computational modelling was used to support the experimental data. In these experiments, the strain rate didn't reach $10^{5} \mathrm{~s}^{-1}$ level, as expected for the stainless steel, and therefore the yield strength increased with strain rate.

Upon inspection the sabot on projectile and flange on target cylinder doesn't have any role in cylinder expansion, hence, the projectile was modelled as solid cylinder of $100 \mathrm{~mm}$ length and target as hollow cylinder without flange (Fig 7). Mesh size of $1 \mathrm{~mm}$ was chosen for all the geometries. No failure models were assigned for mild steel and stainless steel as the interest was only expansion velocity. 

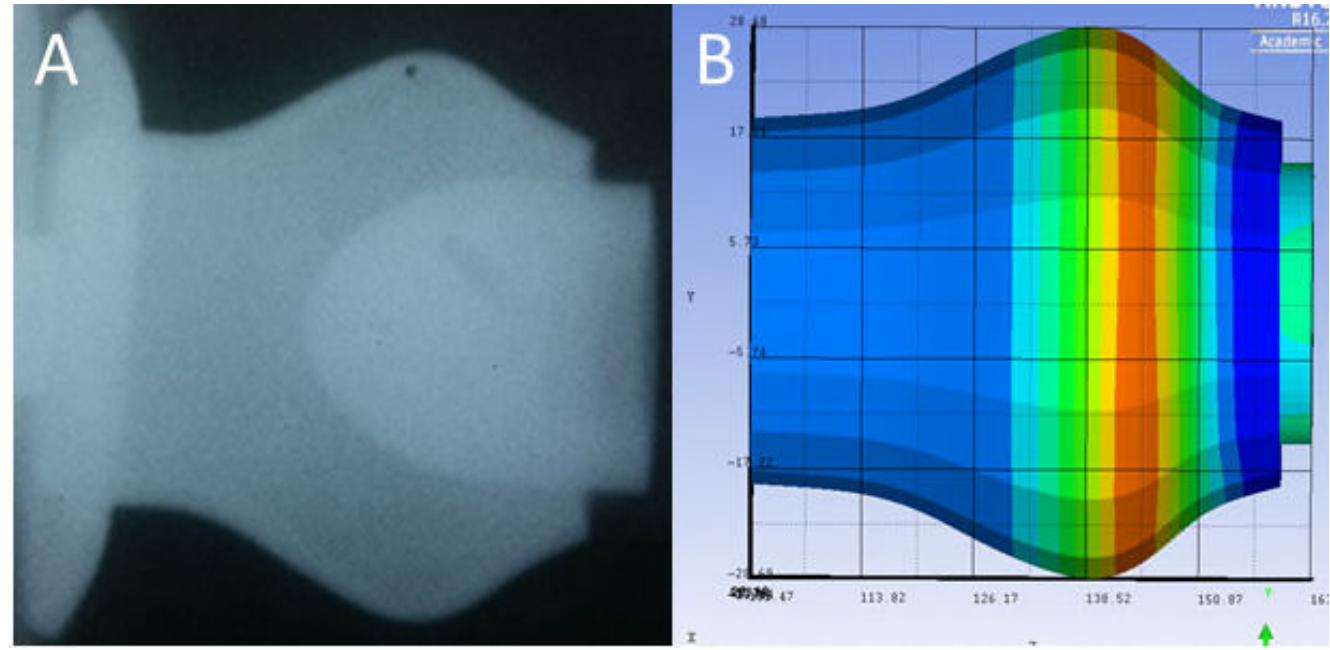

Figure 7. Comparison of expanded cylinder with radiograph for $4 \mathrm{~mm}$ thick MS A) $t=40 \mu s$ and B) $50 \mu \mathrm{s}$

The expansion profile as shown in simulation matched well with radiograph. However, in simulation, it took $50 \mu \mathrm{s}$ for same radial expansion of $4 \mathrm{~mm}$ thick MS cylinder, which was observed after $40 \mu \mathrm{s}$ of impact in the radiograph. Results of simulation are presented in Table 3.

Table 3. Results of simulations

\begin{tabular}{|c|c|c|c|}
\hline $\begin{array}{c}\text { Case } \\
\text { thickness(mm) }\end{array}$ & \multicolumn{2}{|c|}{$\begin{array}{c}\text { Predicted avg. } \\
\text { expansion velocity(m/s) }\end{array}$} & $\begin{array}{c}\text { Experimental } \\
\text { expansion } \\
\text { velocity (m/s) }\end{array}$ \\
\cline { 2 - 4 } & $\begin{array}{c}\text { Mild Steel } \\
(1006)\end{array}$ & SS304 & EN3 \\
\hline 4 & 216 & 204 & 380 \\
\hline 3 & 253 & 241 & - \\
\hline 2 & 300 & 289 & - \\
\hline
\end{tabular}

The simulation results show that expansion velocity increases by about $40 \%$, when thickness reduces from $4 \mathrm{~mm}$ to $2 \mathrm{~mm}$. Also, expansion velocity of SS304 is slower than mild steel (AISI 1006). There is significant difference between predicted and measured expansion velocity. Firstly, the material parameters for actual materials have not been used in model due to unavailability of material data. Secondly, due to 
lack of failure model, the later stage of expansion, when material starts losing strength can't be correctly modelled (Jones et al, 2013). Despite difference in simulation and experimental velocity, the trend could be modelled and approximate estimation of expansion velocity for different thicknesses was obtained.

Recovered mass of the fragmented cylinders varied from 65 to $85 \%$, with recovery being lower for stainless steel than for the mild steel cylinders. Also, recovery was less for thinner cylinders, with the smaller size fragments being more radially dispersed and therefore less likely to be captured in the fibre fragment recovery tube, instead escaping into the surrounding gas expansion part of the target chamber (Figure 1). . In all cases a significant portion of the cylinder from the impact end ( $40-50 \%$ by-mass) was either recovered intact or fractured in just two or three pieces (see Figures 8 and 9). This part, defined as the 'neck' in these studies, was recovered intact for all the mild steel experiments, whereas it was fractured in the case of the 2 and $3 \mathrm{~mm}$ wall thickness stainless steel cylinders. This is likely due, at least in part, to the axial position of the maximum radial expansion; for the mild steel this is closer to the middle of the cylinder than for the stainless steel as shown by the slope gradient in Figures $5 \mathrm{~B}$ and $6 \mathrm{D}$. One of the major differences of this technique from the fragmentation of explosive filled cylinders is that, in the latter case, almost the total mass of the container fragments on explosive loading; whereas, in gas gun experiments, only approximately half of the cylinder undergoes fragmentation. This can be visualised as a localised expansion of a metal cylinder due to partial filling with explosive, where the empty portion does not undergo fragmentation.

Figure 8 shows the recovered components from $4 \mathrm{~mm}$ thick cylinders of stainless steel and mild steel. The broken flange pieces in the case of the stainless steel cylinder and the corresponding intact flange for the mild steel case are visible. Cylinder 'necks' of different sizes for both materials can also be observed; for mild steel the neck mass was $125 \mathrm{~g}$ compared with $95 \mathrm{~g}$ for stainless steel. 


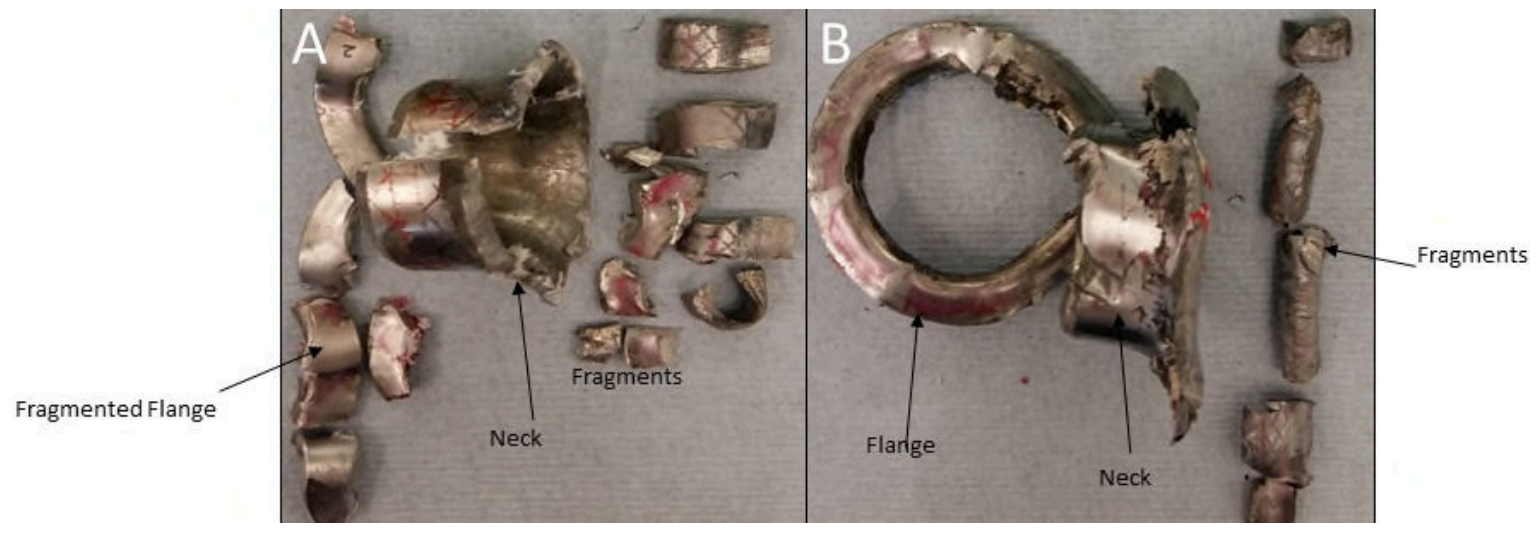

Figure 8. Recovered fragments from the $4 \mathrm{~mm}$ wall thickness cylinders. A) Stainless steel and B) Mild steel.

Similarly, the recovered components from 2 and $3 \mathrm{~mm}$ thickness (both mild and stainless steel) cylinders are shown in Figure 9.

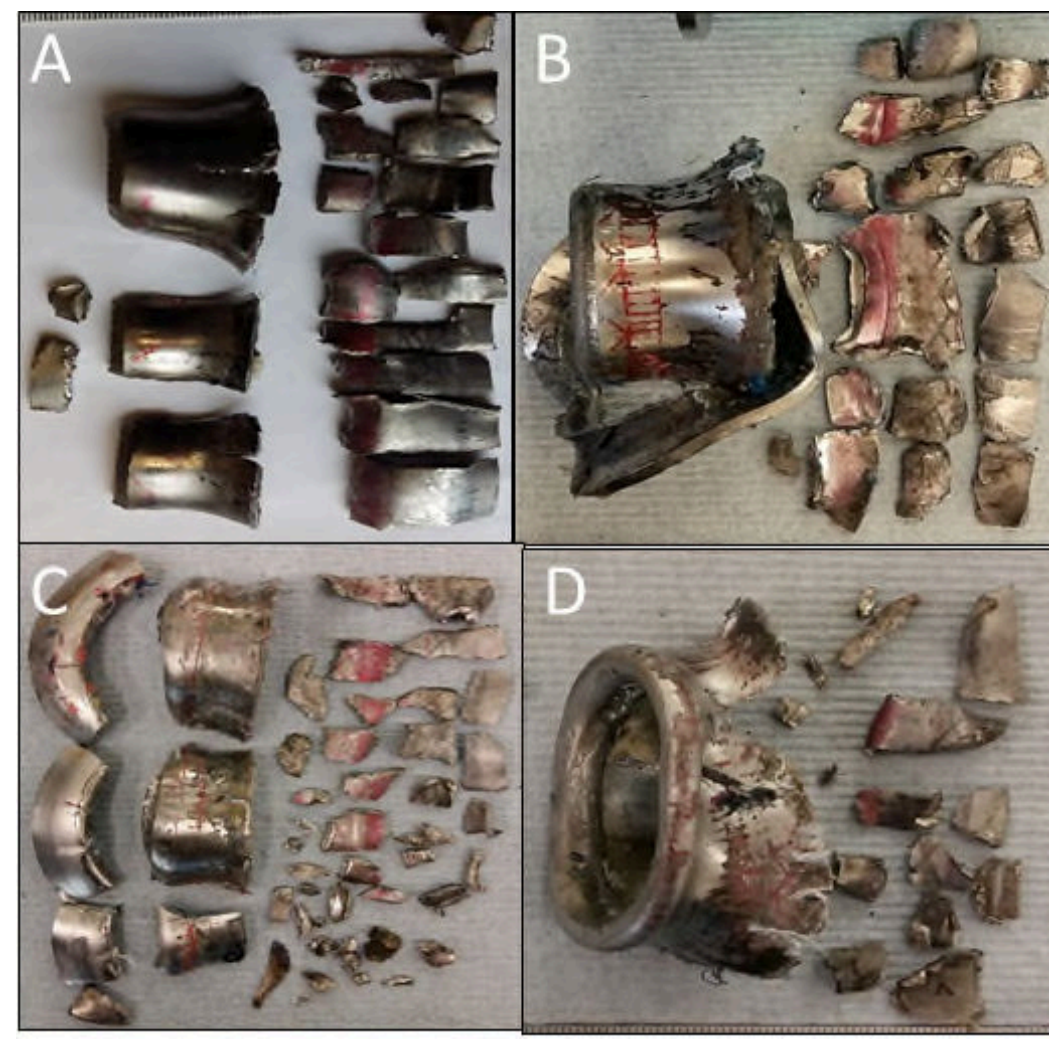

Figure 9. Top row are $3 \mathrm{~mm}$ wall thickness cylinders ( $\mathrm{A}$ and $\mathrm{B}$ ) and bottom row are 2 $\mathrm{mm}$ wall thickness of cylinders ( $C$ and $D)$. $A$ and $C$ are stainless steel, with $B$ and $D$ mild steel. 
As noted in the introduction, there is a significant body of work in the literature focused on the fragmentation of cylindrical metal systems - albeit under explosive loading. For example, the different fracture and fragmentation behaviour of stainless steel and mild steel can be attributed to strain-rate sensitivity and strain hardening. As reported in various studies (Gold and Baker, 2008; Lichtenfeld et al., 2006; Form and Baldwin, 1954), SS 304 strengthens by strain-rate hardening with a drastic reduction in ductility. High work hardening is a property of the austenite phase (ASM, 2018), which results in a greater number of fracture sites initiated along the circumference. A decrease in ductility at the higher strain rates can be explained by shear localization due to adiabatic shear bands (Gold and Baker, 2008). The shear bands are formed when the material is subjected to a critical strain which is independent of strain-rate (Xu et al., 2008), with shear bands observed at strain rates $>10^{3} \mathrm{~s}^{-1}$. Strain-rates within the band reach very much higher values - such that, for example, phase transformation to martensite has been reported for SS 304, within these regions. Hiroe et al. (Hiroe et al., 2008), in studies with explosive filled cylinders, have also noted increased yield strength and decreased fracture ductility of SS 304 as compared to carbon steel at high strain-rates. In similar work, Li and Peng (Li and Peng, 2017) have reported studies on effect of strain hardening on ductility of austenitic stainless steel. It was observed that the fracture elongation decreases with increase in work hardening. Finally, it's worth noting (in line with the study herein) that mild steel also strengthens by high strain-rate loading, but with a lesser effect on ductility (Goto et al., 2008).

Studying the effect of casing thickness, it is apparent that thinner casings expand at higher velocity if the rate of loading is the same. According to Grady and Kipp (Grady and Kipp, 1985), the number of fragments generated increases with the expansion velocity. Similarly, it has been shown (Stronge et al., 1989) that for explosive filled cylinders the fragment size decreases with an increase in charge-to-mass ratio, i.e. thinner casings for the same mass of explosive will always generate greater numbers of fragments of smaller size. Additionally, the incorporation of casing thickness in fragmentation equations has shown that fragment size is directly proportional to the cube root of casing thickness and inversely proportional to the strain-rate (Goloveshkin and Myagkov, 2014). Moreover, the number of fragments has been shown to be inversely proportional to the cube root of the casing thickness (for both thin and thick cases), with the number of fragments increasing as the casing thickness is reduced. 
Also, the fragmentation energy (Grady and Kipp, 1985), i.e. the energy absorbed before fracture, is less in thinner casings, leading to a greater numbers of failure sites. Both these factors support greater numbers of fragments in the case of thinner casings. The details of overall (recovered) fragment distributions, excluding the neck and flange regions, for the experiments reported herein are presented in Table 3 . The results are consistent with the previous studies described above, the anomaly of the mild steel with $2 \mathrm{~mm}$ casing thickness attributed to the low \% recovery of the cylinder mass.

Table 6. Results of fragmentation (where, SS is stainless steel and MS is mild steel).

\begin{tabular}{|c|c|c|c|c|c|c|}
\hline $\begin{array}{c}\text { Casing } \\
\text { thickness }\end{array}$ & \multicolumn{2}{|c|}{$\begin{array}{c}\text { No. of } \\
\text { fragments }\end{array}$} & \multicolumn{2}{|c|}{ (g) } & \multicolumn{2}{c|}{ weight } \\
\cline { 2 - 7 }$(\mathbf{m m})$ & SS & MS & SS & MS & SS & MS \\
\hline 4 & 11 & 05 & 30.93 & 35.78 & 20.20 & 17.15 \\
\hline 4 & 13 & 07 & 37.60 & 29.95 & 23.46 & 15.31 \\
\hline 3 & 21 & 21 & 53.50 & 40.80 & 40.11 & 26.03 \\
\hline 2 & 29 & 16 & 20.88 & 6.78 & 20.50 & 6.21 \\
\hline
\end{tabular}

Table 6 demonstrates that a greater proportion of the stainless steel cylinders were recovered as fragments compared to mild steel. The mass of the recovered neck was consistently $>50 \%$ of cylinder mass in the experiments with mild steel, whereas it was ca. $40 \%$ in the experiments employing stainless steel cases. In studies by Vogler et al. (Vogler et al., 2003), a similar difference was observed between AerMet steel and Uranium alloy. Being harder than steel, a greater mass of Uranium alloy participated in fragmentation. Thus it can be inferred here that due to a greater strain hardening effect, the hardness of stainless steel increases to a greater extent than in the mild steel case. Another difference between the fragmentation of the two materials was the uneven distribution of fragment size in mild steel and fairly uniform mass distribution in the stainless steel case. This is attributed to the microstructure of the different steels. In dual phase mild steel, the grains of ferrite and pearlite behave differently, 
leading to stress concentration at grain boundaries. Also, the cracks can initiate at manganese sulphide inclusions, present in mild steel (Goto et al., 2008). Cracks initiate randomly at certain grain boundaries due to stress concentration at these sites. As stainless steel has a single austenitic structure, cracks would likely be initiated with more uniform distribution. The cylinder neck and fragments from $4 \mathrm{~mm}$ thick cylinders are shown in Figure 10.

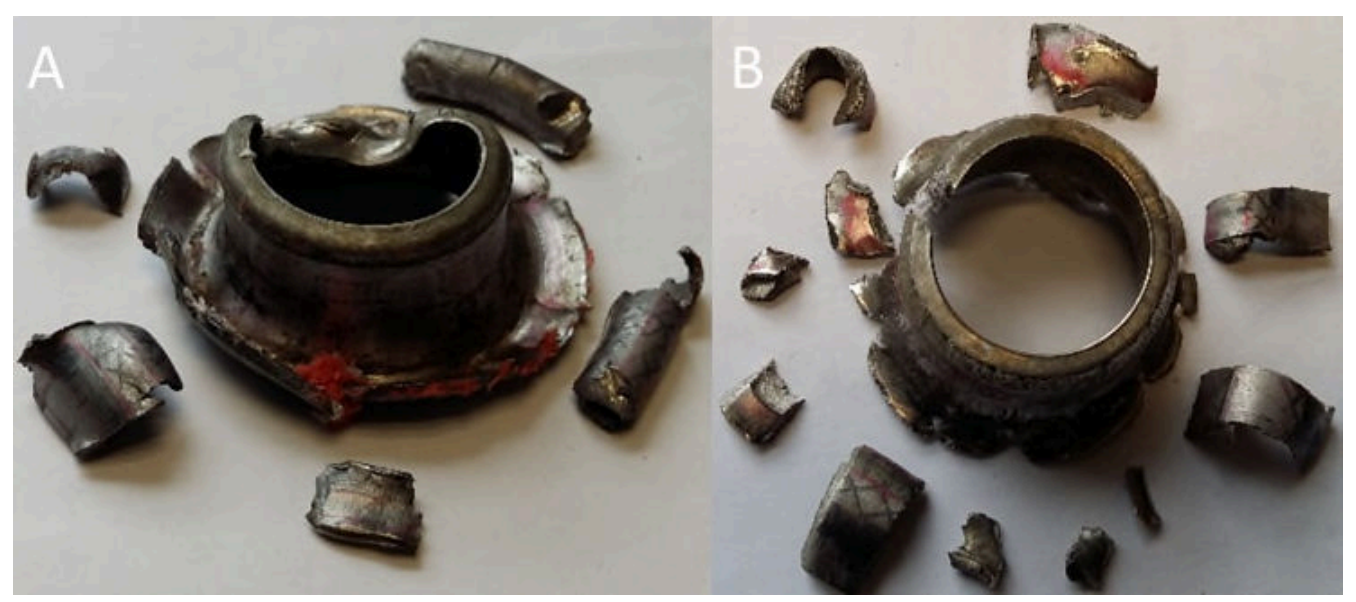

Figure 10. Recovered neck and fragments from 4-mm thick cylinders: A) mild and B) stainless steel.

Figure 10 shows that stainless steel produced longer and more numerous fragments as compared to mild steel. The mild steel cylinder failed in a single vertical plane, producing wider fragments, indicating a lower number of cracks and thus fewer fragments. The smaller fragments in the case of stainless steel broke away from the region of maximum radial expansion, between the neck and longer fragments. From the markings on the fragments, it was evident that the width of fragments in the case of mild steel was more than that for stainless steel. As per Grady's energy theory (Grady and Kipp, 1985), fragment width is directly proportional to fragmentation toughness. Analysing the fragments from the 4-mm thick cylinders, the fragmentation toughness of mild steel seems to be higher than for stainless steel.

As observed, the fracture was a typically ductile failure in both types of steel, with fracture progressing at approximately $45^{\circ}$ to the radius. This is the same as reported in other studies - for example for Titanium cylinders (Jones et al., 2012) - using the 
gas gun technique. The key failure mechanism in both materials is via nucleation and growth of cracks.

Five fragments from each experiment were randomly selected and at least three measurements were taken on each fragment. Fragments, which showed undamaged surfaces on both sides were selected for thickness measurements (to avoid issues from subsequent impacts on gun casing / mounts, etc). Reduction of thickness was maximal along the plane of radial fracture which had expanded to maximum radius before failure. The mean of these thickness readings was taken and is presented in Figure 12.

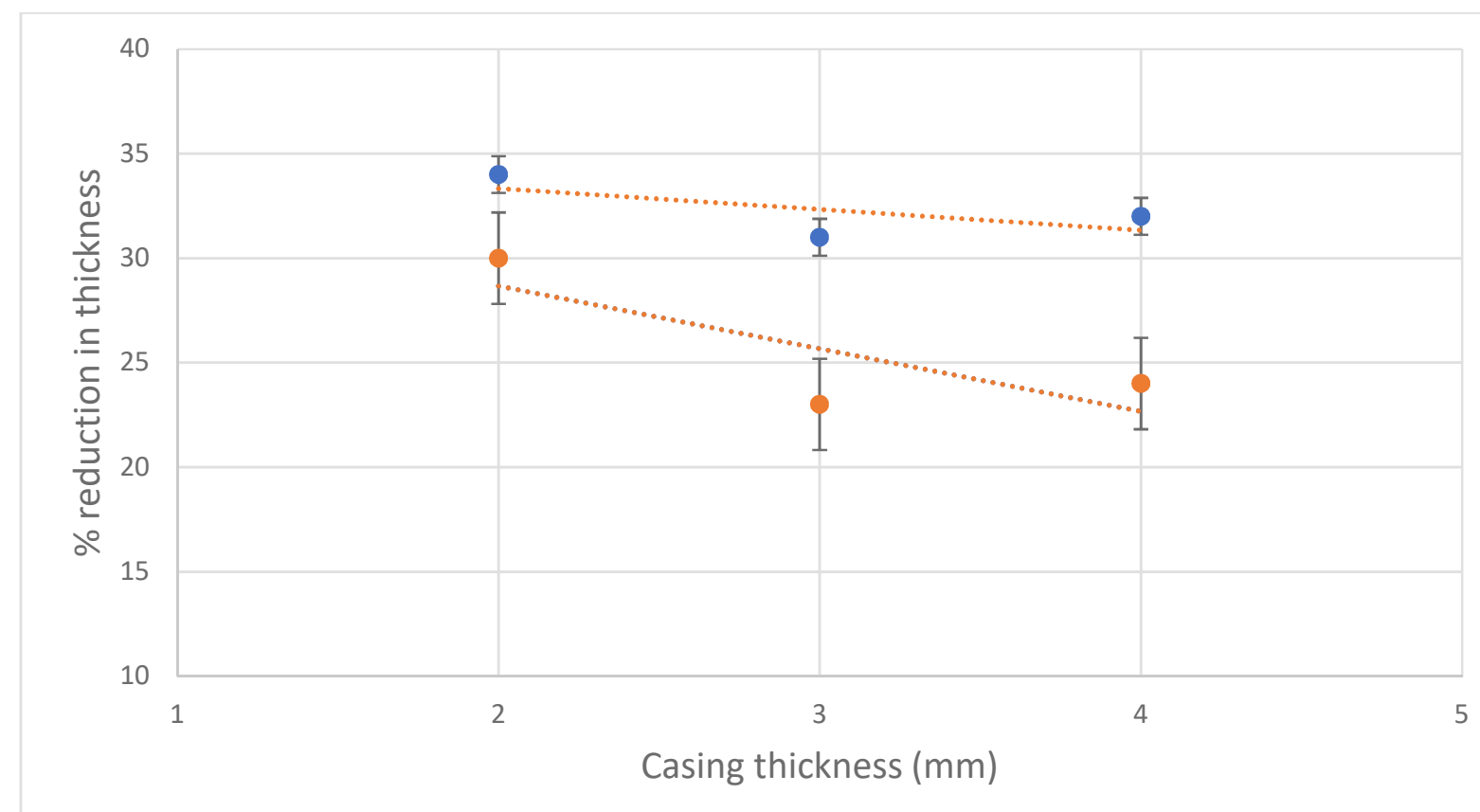

Figure 12. Plot illustrating reduction in thickness of fragments.

There is a greater reduction in thickness of mild as compared to stainless steel, indicating that the mild steel cylinders expanded more than the stainless steel cases before fracture. This again justifies the explanation of greater strain-rate hardening of stainless steel. Further, reduction in thickness is greater for thinner cylinders, which is due to higher strain-rates (due to higher acceleration of lighter, thinner, walled material), resulting in enhanced failure stress and thus more thinning. Reduction in thickness can be correlated to failure strain of the material, i.e. the greater the reduction in thickness, the higher the plastic strain the material undergoes before 
failure (MatWeb, 2018). Fracture strain for AISI 1018 (similar to EN3) has been reported as $46 \%$, at strain-rates of $10^{5} \mathrm{~s}^{-1}$. In another study of stainless steel cylinders by Amott (Amott et al., 2017), failure strain was reported at ca. $25 \%$ at a strain-rate of $8.5 \times 10^{3} \mathrm{~s}^{-1}$. Although this literature data is from nominally different experimental conditions, it gives an approximate indication that failure strain is higher for mild as compared to stainless steel.

FWDM plots based on recovered fragments have been reported to compare the relative power of explosively driven cylinders (Oxley et al., 2018; Bors et al., 2014). FWDM were plotted for the recovered fragments in all the experiments. In FWDM, abscissa $(x)$ is ratio of weight of individual fragment $\left(\mathrm{m}_{\mathrm{f}}\right)$ to total weight of recovered fragments $\left(\mathrm{Mr}_{\mathrm{r}}\right)$ and ordinate $(\mathrm{y})$ uses sum of fragment weight with all fragments heavier than it (Mcum), normalised by total weight of recovered fragments $\left(\mathrm{Mr}_{\mathrm{r}}\right)$. A straight line is plotted through the data points and gradient / slope of this line has been shown to indicate the relative power of the resultant explosion; with steeper gradient implying greater power. However, in non-explosive expansion, the slope can show differences in strain rate and material properties of casings. Figures 13 and 14 show such FWDM plots for the stainless and mild steel cylinders considered in this study, respectively.

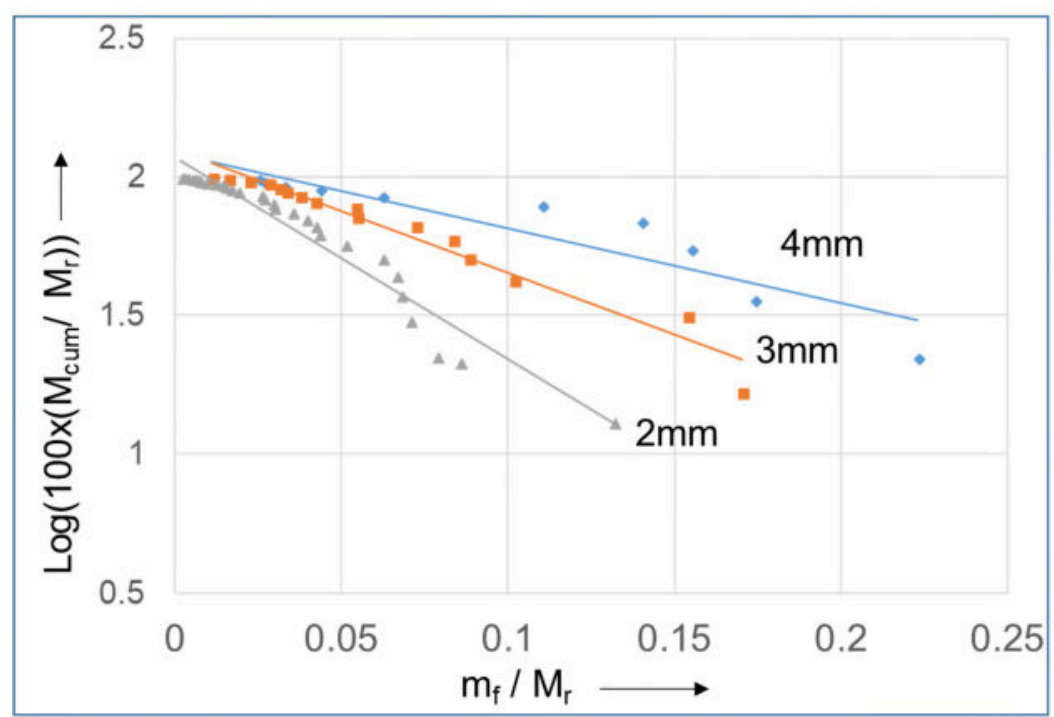

Figure 13. Plot showing FWDM gradient for stainless steel 304 cylinders. 


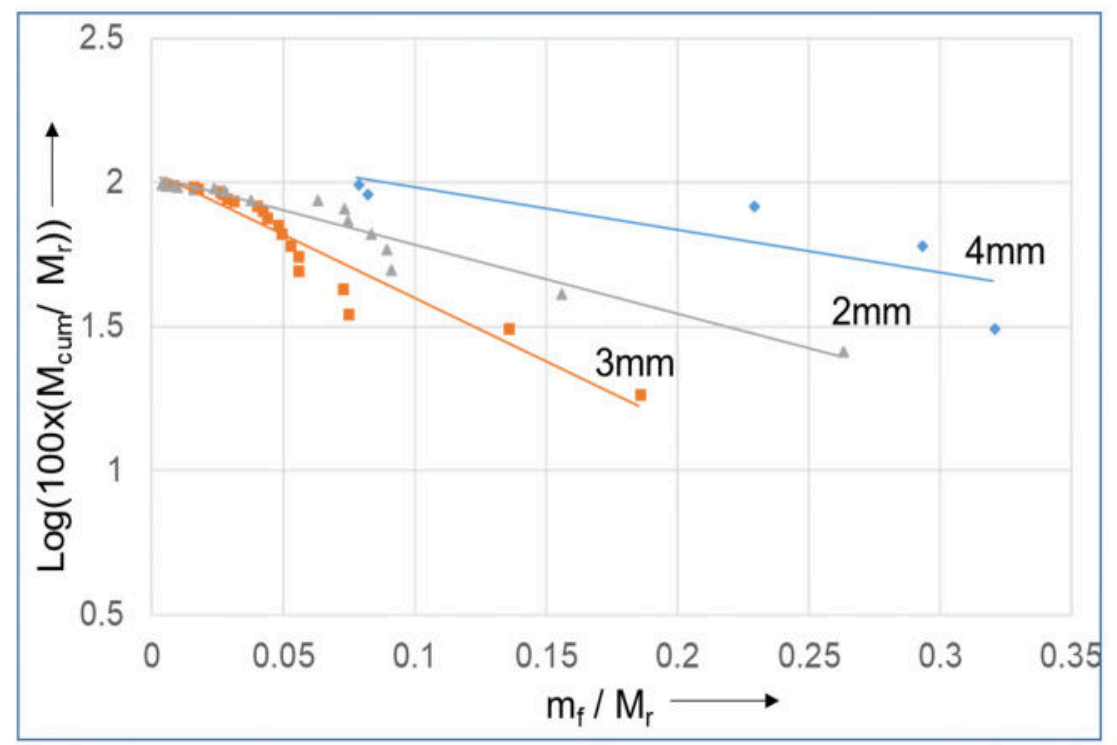

Figure 14. Plot showing FWDM gradients for EN3 mild steel cylinders.

The FWDM data for stainless steel presented in Figure 13 shows a clear trend between thickness and slope / gradient, demonstrating the effect of higher strain-rates. The magnitude of the gradient for the 3-mm thick cylinder is greater than that for the 2-mm thick mild steel cylinder recorded in Figure 14 - potentially attributable to poor recovery of fragments in the latter case. This data brings out the limitation of FWDM analysis in cases where the recovery (of fragments) is very low. The same issue has been discussed by Oxley et al. (Oxley et al., 2018), in that lower recovery can significantly change the resultant gradient / slope. The gradient for stainless steel is higher than that for mild steel in all cases, implying enhanced fragmentation characteristics.

Figure 15 shows comparative FWDM gradients of 2-mm thick cylinders of stainless and mild steel. Representative slopes for deflagration and detonation reported by Oxley et al. (Oxley et al., 2018) are included (based on 50+ steel pipe bomb experiments) and indicate that FWDM slopes for the experiments considered herein lie between deflagration (slope <2) and detonation (slope $>13$ ). However, it's worth noting that the magnitude of these gradients are not absolute, and are dependent on casing material, thickness, pipe size, method of initiation, etc. 


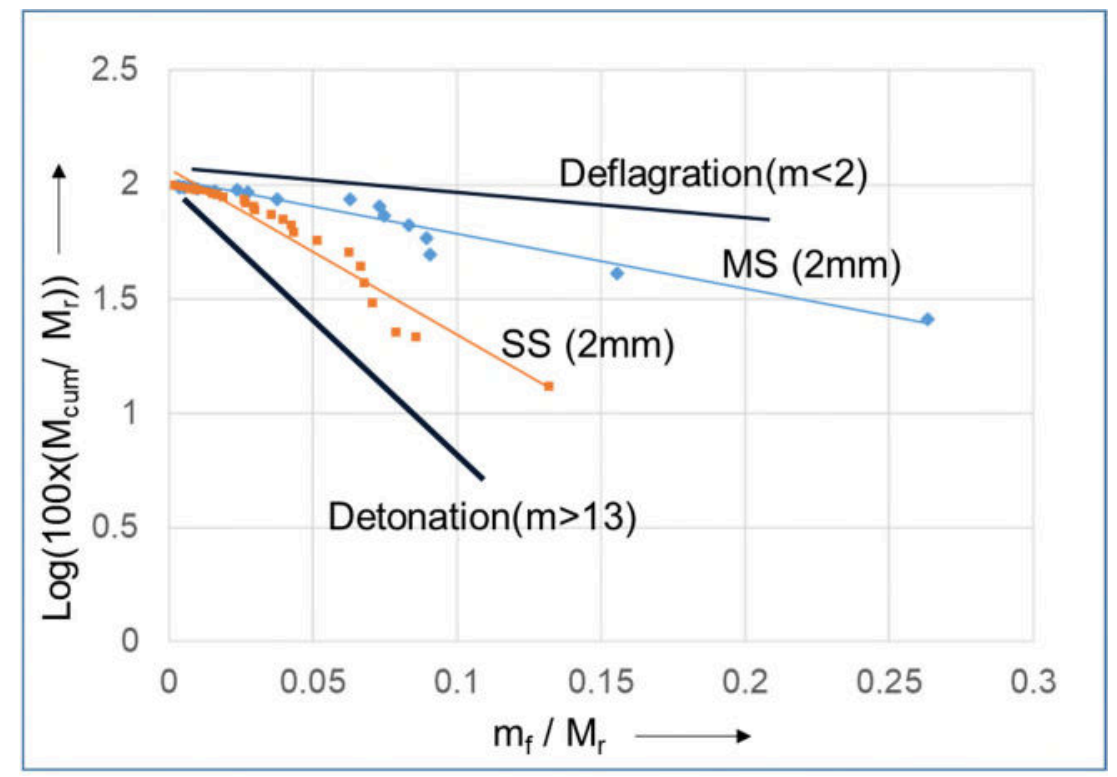

Figure 15. Plot comparing FWDM gradients for stainless and mild steel.

The slope of a FWDM can be correlated to stain-rates, i.e. lower strain-rates in deflagration to much higher rates in detonation. Bors et al. (Bors et al., 2014) has reported expansion velocities of 70 to $130 \mathrm{~m} \mathrm{~s}^{-1}$ for deflagrating fillers like pyrodex and double base smokeless powder; whereas expansion velocities in case of detonation are more than $1,000 \mathrm{~m} \mathrm{~s}^{-1}$ (Ren et al., 2016). Similar expansion velocities can be easily realised by gas-gun driven cylinder expansion by varying the input parameters, although the latter (detonation-relevant) expansion velocities would require use of twostage launchers. Such data in the form of FWDMs at different strain rates / expansion velocities can be helpful to indicate the type of filler used by comparison with FWDM of recovered fragments from site of explosion.

Optical microscopy was utilised to analyse the recovered mild steel fragments. The samples were mounted, ground and etched using nital. 


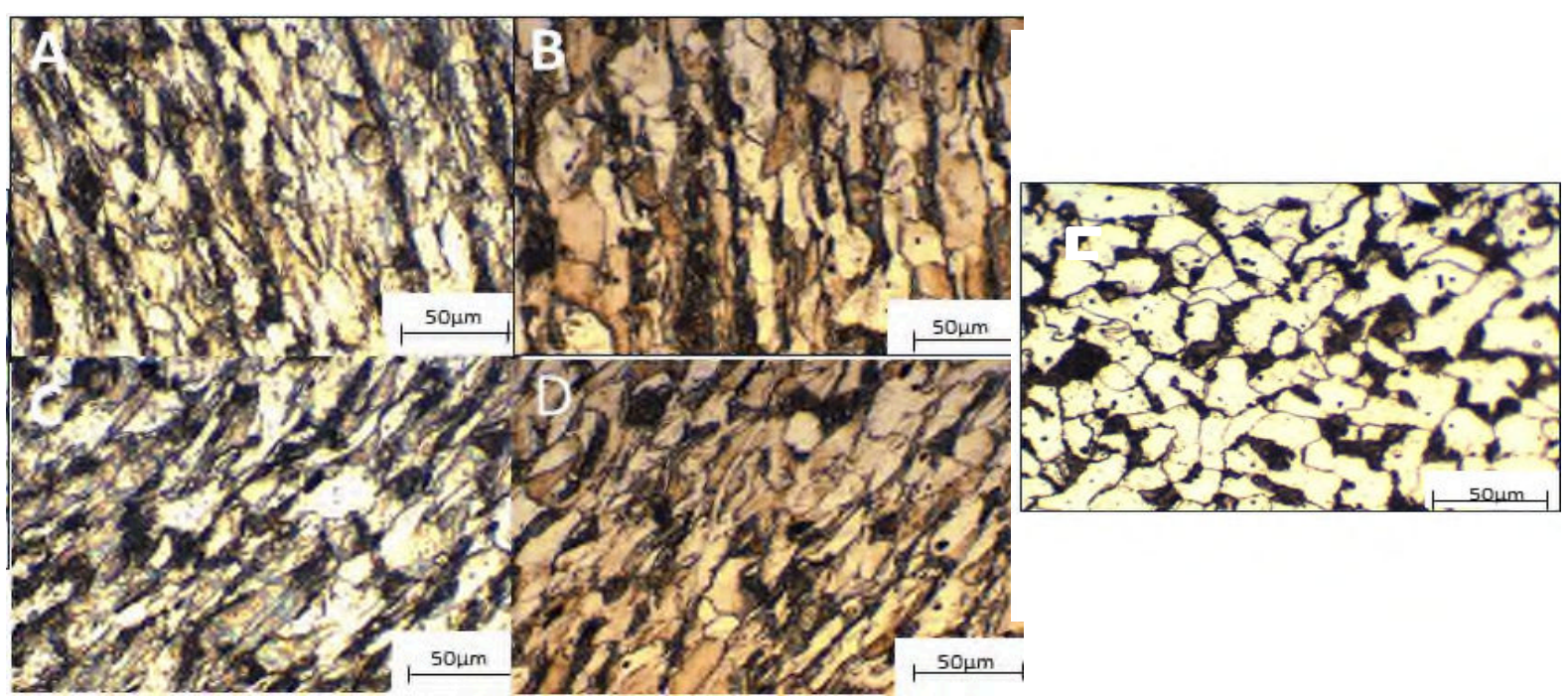

Figure 16. Microstructure of EN3 mild steel. A) $3 \mathrm{~mm}$ wall thickness, B) $2 \mathrm{~mm}$ wall thickness, C) $3 \mathrm{~mm}$ wall thickness adjacent to fracture surface and D) $2 \mathrm{~mm}$ wall thickness adjacent to fracture surface E) As received EN3.

A sample was cut from as received EN3 steel rod to observe the microstructure for reference. Microstructure of as received EN3 along length of the cylinder (Figure 16) consists of randomly distributed grains of ferrite (bright) and pearlite (dark). An interesting pattern of aligned ferrite (light) and pearlite (dark) grains was observed in fragments. The pearlite grains are elongated and form continuous bands. Grains adjacent to fracture appear more deformed and elongated (still in continuous bands). Gregory et al. (Gregory et al., 2010) has reported that for high power fillers, the pearlite was highly distorted in continuous bands, which extended beyond a single grain or colony. Hence, it can be tentatively inferred that strain-rates encountered in the (gasgun driven) experiments reported in this study are sufficiently high to cause microstructural effects similar to those from energetic expansion methods. Importantly, with the current technique, these effects could be further characterised by ready variations of loading (and therefore strain) rate, to provide further insight into material failure. 


\section{Conclusions}

In this study the gas-gun technique was employed to investigate fragmentation of differing mild and stainless steel cylinders. The experimental approach proved an effective technique to study both failure and fragmentation characteristics of materials, which was supported by the computational study. In particular, the control over strain rates and option of various diagnostic techniques (in a laboratory setting) makes it an attractive method. Key findings were:

- Stainless steel, due to its austenitic structure, is more sensitive to strain rate hardening.

- Increased strength and decreased ductility meant that a greater mass of stainless steel cylinders $(<10-15 \%)$ participated in fragmentation as compared to mild steel.

- Stainless steel consistently produced more uniform fragmentation in terms of fragment mass distribution. It is of particular note that, to the authors knowledge, use of FWDM for non-explosive fragmentation (as employed here) has never been reported in the literature. This analysis gave a new perspective to compare performance of casing materials and effect of strain rate of FWDM.

- Decreasing cylinders wall thickness increased fragment numbers, but decreased size and mass of the same - this was attributed to thinner casings being subjected to a higher velocity and subsequent higher strain-rates.

- The microstructure of failed material was shown to be very similar to that reported in the literature for explosively driven radial failure. This suggests the potential to further investigate strain-rate effects in a useful manner with the current technique. Although, it's worth noting that the gas-gun technique does not replicate fragment target effects, direction and velocity (for example, of shells). However, the current approach will allow for minimisation of expensive and complex explosive-driven fragmentation tests.

Overall, this paper has clearly demonstrated the potential of gas-gun driven cylinder expansion experiments to not only simulate (in a controlled laboratory setting) explosively-driven tests, but also - more importantly - to allow access to strain-rates around these regions with much greater fidelity. This holds out the potential to explore material failure at a microstructural level as fragments form, something which 
explosive loading does not allow - in turn, providing insight into how to optimise - or mitigate - such failure modes.

\section{References}

Al-Hassani STS, Hopkins HG, Johnson W. A Note on the fragmentation of tubular bombs. Int. J. Mech. Sci. 1969;11:545e9.

Amott $\underline{\mathrm{R}}$, Harris $\underline{\mathrm{EJ}}$, Winter $\underline{\mathrm{RE}}$, Stirk $\underline{\mathrm{SM}}$, Chapman $\underline{\mathrm{DJ}}$, Eakins DE. The fracture and fragmentation behaviour of additively manufactured stainless steel 316L. AIP Conference Proceedings 1793, 100002 (2017).

ASM Aerospace Specification Metals Inc.

http://asm.matweb.com/search/SpecificMaterial.asp?bassnum=mq304a (Accessed: 05 June 2018)

Bors D, Cummins J, Goodpaster J. Anatomy of a pipe bomb explosion - measuring the mass and velocity distribution of container fragments. For Sci Int 2014; $234: 95$ 102.

Cao Y, Ahlström J, Karlsson B. The influence of temperatures and strain rates on the mechanical behaviour of dual phase steel in different conditions. J Mater Technol $2015 ; 4: 68-74$.

Form G, Baldwin Jr WM. The influence of strain rate and temperature on the ductility of austenitic stainless steel-the effects of stress concentration and triaxiality on the plastic flow of metals. Case Inst of Tech Cleveland Oh Metals Research Lab; 1954.

Gold VM, Baker EL. A model for fracture of explosively driven metal shells. Eng. Fract. Mech. 2008;75:275-89.

Goloveshkin VA, Myagkov NN. Fragmentation model for expanding cylinder. Int. J. Fract. 2014;187:239-43.

Goto DM, Becher R, Orzechowski TJ, Springer HK, Sunwoo AJ, Syn CK. Investigation of the fracture and fragmentation of explosively driven rings and cylinders. Int J Impact Eng 2008;35:1547-56.

Grady DE. Fragmentation of rings and shells. Springer; 2006. 
Grady DE. Investigation of explosively driven fragmentation of metals-twodimensional fracture and fragmentation of metal shells, Progress Report II, US. Department of Energy, Lawrence Livermore National Laboratory, UCRL-CR-152264, B522033, 2003.

Grady DE, Kipp ME. Mechanisms of dynamic fragmentation: factors governing fragment size, Mech. Mater. 4 (3e4) (1985) 311e320.

Grady DE, Benson DA. Fragmentation of metal rings by electromagnetic loading. Exp Mech 1983;23:393-400

Gregory O, Oxley J, Smith J, Platek M, Ghonem H, Bernier E. Microstructural characterization of pipe bomb fragments. Mater Charact 2010;61(3):347-54.

Gurney RW. The initial velocity of fragments from bombs, shells and grenades, Army Ballistic Research Laboratory Report No. 405, 1943.

Hiroe T, Fujiwara K, Hata H, Takahashi H. Deformation and fragmentation behavior of exploded metal cylinders and the effects of wall materials, configuration, explosive energy and initiated locations. Int J Impact Eng 2008;35:1578-86.

Jones D R, Chapman D J and Eakins D E. Gas gun driven dynamic fracture and fragmentation of Ti-6Al-4V cylinders. J Phys 2014; Conf Ser. 500: 112037.

Jones D R, Chapman D J, Eakins D E. A gas gun based technique for studying the role of temperature in dynamic fracture and fragmentation. J. Appl. Phys 2013. $114: 173508$.

Jones D R, Eakins DE, Hazell PJ, Chapman DJ and Appleby-Thomas GJ. Development of gas gun driven expanding cylinder technique" AIP Conf. Proc 2012; 1426:1141-1144.

Li K, Peng J. Mechanical Behavior of 316L Stainless Steel after Strain Hardening. In MATEC Web of Conferences 2017 (Vol. 114, p. 02003). EDP Sciences.

Lichtenfeld JA, Mataya MC, van-Tyne CJ. Effect of strain rate on stress-strain behaviour of alloy 309 and 304L austenitic stainless steel. Metallurgical and Materials Transactions A 2006;37A:147. 
MatWeb Material Property Data.

http://www.matweb.com/search/datasheet.aspx?matguid=b57ab1b769db483e9117f 7570895f0ea\&ckck=1 (Accessed: 05 June 2018).

Mott NF. Fragmentation of shell cases. Proc. R. Soc. Lond. A. 1947;189(1018):3008.

Mott NF, Linfoot EH. A Theory of Fragmentation, Extra-Mural Research No. F72/80, Ministry of Supply, A. C. 3348 (Jan 1943).

Moxnes JF, Prytz AK, Froyland O, Klokkehaug S, Skriudalen S, Friis E, et al. Experimental and numerical study of the fragmentation of expanding warhead casings by using different numerical codes and solution techniques. Def Technol 2014;10:161-76.

Oxley JC, Smith JL, Bernier ET, Sandstrom F, Weiss GG, Recht GW, Schatzer D. Characterising the performance of pipe bombs. J For Sci 2018; 63(1):86-101.

Oxley JC, Smith JL, Resende E, Rogers E, Improvised Explosive Devices: Pipe Bombs, J Forensic Sci 2001; 46 (3): 87-110

Qui L, Yu Y, Xiong Q, Deng C, Hun X and Liang L, Analysis of Electromagnetic Force and Deformation behaviours in Electromagnetic Tube expansion with concave coil based on Finite element method, EEE Trans Appl Superconductivity. 2018 Apr $28(3)$

Shui-Sheng YU, Yu-Bin LU, Yong CA. The strain-rate effect of engineering materials and its unified model. Latin American Journal of Solids and Structures. 2013 Jul;10(4):833-44.

Steinberg DJ, Cochran SG, Guinan MW. A constitutive model for metals applicable at high-strain rate. Journal of Applied Physics. 1980;51(3):1498-504.

Stirk S M, Winter R E, Keightley P T. Microstructural analysis of expanded stainless steel 304 cylinders. in Proceedings of the SEM 2009 Conference, 2009.

Stronge WJ, Ma XQ, Zhao LT. Fragmentation of explosively expanded steel cylinders. J Mech Sci 1989;31:811-23. 
Ren GW, Guo ZL, Fan C, Tang TG, Hu HB. Dynamic shear fracture of an explosively-driven metal cylindrical shell. Int. J Impact Eng 2016; 95:35-9.

Vogler TJ, Thornhill TF, Reinhart WD, Chhabildas LC, Grady DE, Wilson LT. Fragmentation of materials in expanding tube experiments. Int J Impact Eng 2003; 29:735-46.

Wilson LT, Reedal DR, Kipp ME, Martinez RR, Grady DE. Comparison of calculated and experimental results of fragmenting cylinder experiments. In: Staudhammer KP, Murr LE, Meyers MA, editors. Fundamental issues and applications shock-wave and high-strain-rate phenomena. Elsevier Science Ltd.; 2001. p. 561-9.

Winter RE, Prestidge $\mathrm{H}$. A technique for the measurement of the high strain rate ductility of metals, J Mater Sci 13; 1978:1835-37.

Xu Y, Zhang J, Bai Y, Meyers MA. Shear localization in dynamic deformation: microstructural evolution. Metallurgical and materials transactions A. $2008 \mathrm{Apr}$ $1 ; 39(4): 811$. 